\title{
EDICIÓN Y ESTUDIO DE LA CAPITULACIÓN, ASIENTO Y CONCORDIA ACORDADA POR EL MARQUÉS DE VILLENA CON LOS VECINOS DE SAN JUAN DE VILLAMALEA (1516-1531)*
}

\section{CAPITULACIÓN, ASIENTO Y CONCORDIA ACORDADA POR EL MARQUÉS DE VILLENA CON LOS VECINOS DE SAN JUAN DE VILLAMALEA (1516-1531)'S EDITION AND STUDY}

\author{
IVÁN Gómez CABALLERo \\ Doctorando en la Facultad de Letras \\ UCLM, Ciudad Real, España \\ ivangomezcaballero29@gmail.com
}

Cómo citar este artículo: Gómez Caballero, I. (2021). Edición y estudio de la Capitulación, asiento y concordia acordada por el marqués de Villena con los vecinos de san Juan de Villamalea (1516-1531). Al-Basit (66), 247-277. http://doi. org/10.37927/al-basit.66_6

Recibido/Received: 22-08-2020

Aceptado/Accepted: 05-10-2020

RESUMEN: El presente artículo trata de dilucidar las circunstancias históricas del texto Capitulación, asiento y concordia acordada por el marqués de Villena con los vecinos de San Juan de Villamalea, que se ha transmitido a partir de una tradición indirecta en dos manuscritos apógrafos custodiados en el Archivo Municipal de Villamalea (Albacete) y en el Archivo Histórico de la Nobleza (Toledo). En este sentido, realizamos, por un lado, la primera edi-

\begin{abstract}
This article tries to elucidate the historical circumstances of the text Capitulación, asiento y concordia acordada por el marqués de Villena con los vecinos de San Juan de Villamalea, which has been transmitted from an indirect tradition in two apograph manuscripts kept in the Municipal Archive of Villamalea (Albacete) and in the Historical Archive of the Nobility (Toledo). In this regard, we address, on the one hand, the first critical edition
\end{abstract}

\footnotetext{
* Este trabajo ha sido financiado gracias a una beca de iniciación a la investigación para estudiantes de másteres universitarios oficiales, dirigida por Rafael González Cañal y cofinanciada por el Banco Santander y la Universidad de Castilla-La Mancha durante el curso 2020/2021.
} 
ción crítica del texto a partir de la ecdótica neolachmanianna con un aparato de variantes, $y$, por otra parte, su estudio histórico.

PALABRAS CLAVE: San Juan de Villamalea; marquesado de Villena; edición crítica. of the text based on the neolachmanianna ecdotic with a variants system and, on the other hand, its historical study.

KEYWORDS: San Juan de Villamalea; Villena's marquisate; critical edition.

A mi abuelo Fernando Caballero Valero, por transmitirme el amor a mi pueblo.

\section{ESTUDIO}

En la primera mitad del siglo XIII y hasta finales del siglo XV, Albacete era una tierra inhóspita por su cercanía al reino musulmán de Granada, por lo que existían solamente pequeños núcleos de población. Ya desde comienzos de la Baja Edad Media hasta la actualidad, el norte de la provincia de Albacete ha cambiado las delimitaciones comarcales y provincianas, perteneciendo, en ocasiones, al Estado de Jorquera, a la provincia de Cuenca, a la de Murcia y también a la de Albacete. En aquellos años, existían pequeños núcleos de población cerca de Jorquera o Carcelén, siendo Chinchilla de Montearagón y Alcaraz las ciudades más pobladas e importantes de nuestra provincia (Pretel Marín, 1979, 1982).

Desde finales del siglo XV, después de la Guerra Civil, parte de la actual provincia de Albacete fue gobernada por Diego López Pacheco y Portocarrero (1474-1529), segundo marqués de Villena (Pretel Marín, 1979: pp.7-8). Durante sus años de marquesado, Diego López Pacheco impulsó la creación de nuevos municipios al norte de Albacete y al sur de Cuenca en el Estado de Jorquera, que ya había sido promocionado por Alfonso X el Sabio desde 1266, agrupando de esta forma a varias aldeas, como Boniches, Fuentealbilla, Valde- 
ganga, Carcelén, Alcalá del Júcar y Villa de Ves, además de Cenizate a finales del siglo XIV, concretamente en 1358, casi doscientos años antes que Villamalea, gobernando Benito Pérez, merino de Iniesta (Pretel Marín, 1982: p.123; Almendros Toledo, 2000: pp.57-62).

El presente artículo trata de estudiar, por un lado, las circunstancias históricas de la creación de San Juan de Villamalea, tanto en su propio como en el de pueblos aledaños, y, por otro, realizar la primera edición crítica y anotada del texto, fundamentada, a su vez, en la metodología de la crítica ecdótica neolachmanianna (Blecua Perdices, 1983; Pérez Priego, 1997) de los manuscritos apógrafos AMV-17/2 del Archivo Municipal de Villamalea (Albacete) y FRIAS, C.738,D.1-9 del Archivo Histórico de la Nobleza (Toledo). De esta forma, pretendemos paliar la falta de estudios sobre el pueblo de Villamalea y realizar la primera edición crítica del texto. Nuestro análisis, sin embargo, no pretende agotar todas las posibilidades de estudio de Villamalea en el siglo XVI.

La ecdótica no pretende, por tanto, una mera transcripción literal del texto, conocida como edición paleográfica, ${ }^{1}$ puesto que pretende ir más allá, analizando la transmisión textual, detectando las lectiones en el aparato de variantes e, incluso, restituyendo el léxico en caso de erratas. El ejercicio ecdótico está formado por varias fases diferentes, tales como la recensio, la collatio codicum, la examinatio, la selectio, la constitutio stemmatis, la constitutio textus, el apparatus criticus y, por último, una corrección de pruebas o una nueva collatio codicum. Asimismo, queremos dejar constancia de que la crítica textual es un ejercicio aproximativo - y también especulativo - con el que pretendemos acercarnos a la edición autógrafa del texto original. No obstante, somos conscientes de la enorme dificultad de nuestra tarea, puesto que no conservamos ningún manuscrito autógrafo, pero sí dos manuscritos apógrafos que pueden llevar varios errores

\footnotetext{
${ }^{1}$ Vid. las ediciones paleográficas sobre la ciudad y la provincia de Albacete (Carrilero Martínez, 1997a, 1997b, 2000, 2001, 2002, 2004, 2005).
} 
La recensio consiste en acceder a todos los testimonios posibles de la obra para saber si el manuscrito ha llegado a la actualidad a partir de una transmisión directa o indirecta. Durante esta fase, tenemos que conocer si existe un texto autógrafo del autor o de un copista cercano a él, además de estudiar la tradición textual impresa y discernir entre ejemplar y edición. Procederemos, seguidamente, a enumerar los párrafos del texto y, una vez realizada esta tarea, iniciaremos la collatio codicum ${ }^{2}$, con la que se cotejarán los testimonios entre sí para establecer las variae lectiones a partir del codex optimus, que coincidirá con el antiquor, y quizá no con la editio princeps. En nuestra edición, identificaremos, pues, al codex vetustissimus o codex antiquor como el codex optimus, aunque sabemos que este criterio, si bien facilita la edición, puede no ser adecuado por existir una transmisión textual subarquetípica desconocida y perdida en el stemma codicum. Habiendo realizado ya la collatio codicum, nos encontramos con las variae lectiones de nuestra comedia, cuyos errores no hacen referencia al modelo ideal $(\Omega)$ ni tampoco al modelo arquetipo $(\chi)$ o subarquetípico $(\alpha)$, en caso de existir, sino al testimonio base o codex optimus. Posteriormente, iniciaremos la constitutio stemmatis para reconstruir el codex archetypus $(\chi)$, del que deriva la tradición textual de la obra, discerniendo entre errores comunes, separativos, conjuntivos, poligenéticos y monogenéticos.

\footnotetext{
${ }^{2}$ Intentaremos seguir al máximo los consejos de Alberto Blecua (1983: p.45): «el cuidado de estas labores debe ser extraordinario porque un deficiente cotejo puede provocar errores irremediables en la filiación».
} 


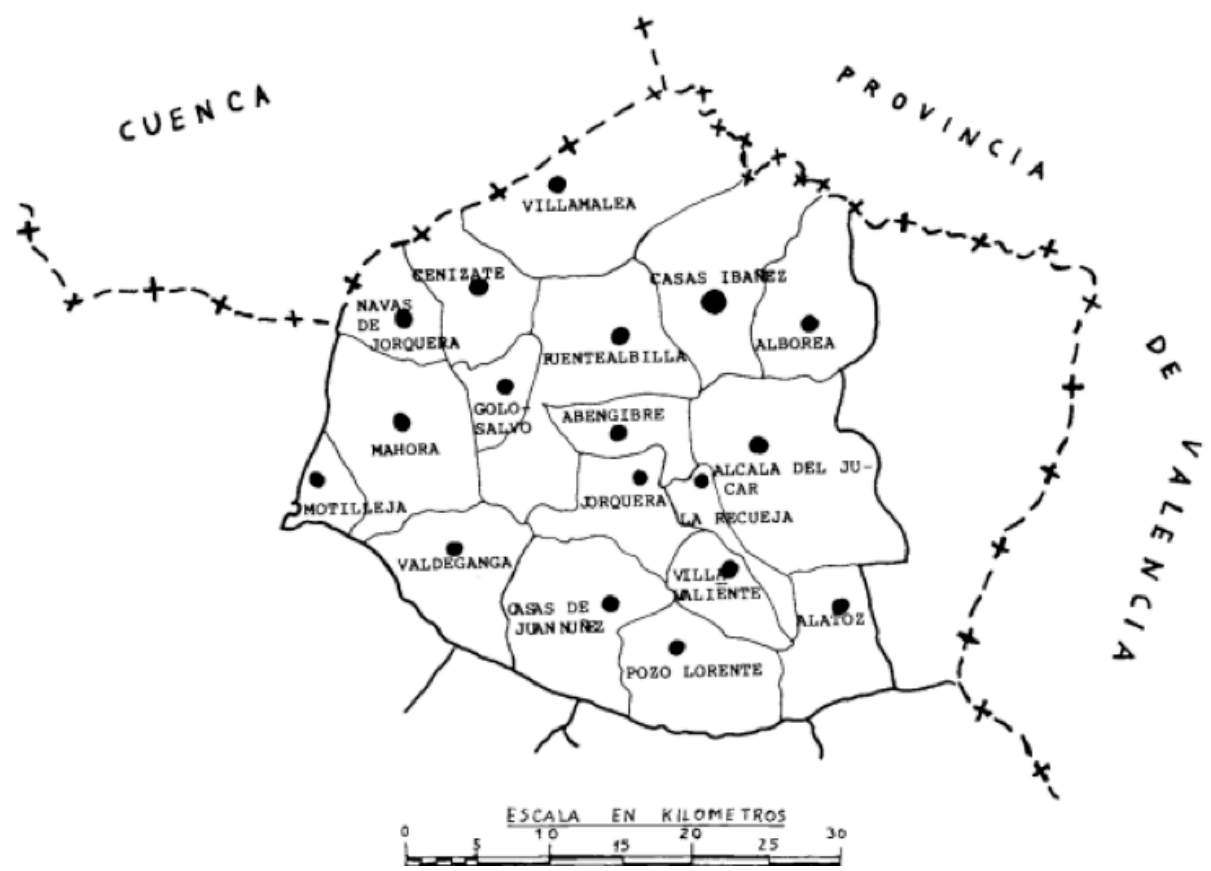

Figura I. Mapa del antiguo Estado de Jorquera. Fuente: Almendros Toledo (1987: p.28).

El actual pueblo de Villamalea se fundó en Fuentealbilla el martes 29 de abril de 1516, perteneciendo, pues, al conocido Estado de Jorquera. Otros poblados aledaños, como, por ejemplo, Madrigueras, Tarazona de la Mancha y Villagordo del Júcar estaban adscritos a la Villa de Alarcón, perteneciente también al Marquesado de Villena (García Moratalla, 2005: p.19). La mayoría de pueblos que conocemos al noreste de Albacete se fundaron en fechas próximas y dependían administrativamente del Estado de Jorquera, un territorio poco poblado sin apenas actividad económica con unas estructuras sociales «en unos casos» ausentes y «en otros» muy débiles.

En sus orígenes, se llamó San Juan de Villamalea, pero no podemos confirmar con seguridad en qué fechas cambió su denominación y tampoco las causas. La etimología del topónimo de «Villamalea» está documentada, ya que proviene del castellano, y este, a su vez, del latín («villa») y también del árabe («maliha»), es decir, significa «ciudad hermosa o bonita» (Pocklington, 2010: p.148). 
Como indica Esperanza Blasco Liante (2017: p.135), existía a principios de siglo una casilla llamada Malea y una pequeña ermita de San Juan Bautista, por lo que, en un primer momento, recibió el sobrenombre dedicado a su patrón, ${ }^{3}$ haciendo, a su vez, referencia, a la primera casa que existió en el lugar. En las Relaciones topográficas de Felipe II (Carrilero Martínez et alii, 2014), fechadas en la década de los 70 del siglo XVI, aparece como Villamalea (fols. $626^{\mathrm{v}}$ y $627^{\mathrm{r}}$ ). Posteriormente, en las Relaciones geográfico-históricas de Albacete de Tomás López, datadas entre 1786 y 1789, se indica que el municipio se llamó en los albores de su fundación San Juan de Villamalea, sin indicar exactamente cuándo se alteró su designación, indicando, además la existencia de la casilla de Malea (Rodríguez de la Torre y Cano Valero, 1987: p.296).

El gobierno municipal de los pueblos albaceteños en aquellos años solía estar compuesto por alcaldes pedáneos y ordinarios, alguaciles, alcaldes de hermandad y cuadrilleros. Además, en las aldeas pertenecientes a Jorquera, era frecuente que el marqués de Villena nombrase al corregidor de la localidad y el concejo del pueblo a los cargos de las aldeas, en principio, con cierta autonomía (Carrilero Martínez et alii, 2014: p.340). La administración local se regía por la ordenanza de fueros, al igual que en el resto de los pueblos albaceteños, por la que todos los oficios se renovaban el 29 de septiembre, día de San Miguel (Rouoil, 1968: p.293). Así, en la actual capital de Albacete la elección de los cargos públicos también se celebraba el mismo día, a excepción de los procuradores síndicos de la «universidad» (Pretel Marín, 2010: p.125).

La administración de San Juan de Villamalea a principios del siglo XVI se estructuraba en dos alcaldes pedáneos, que tenían potestad jurídica, y en dos regidores. Los alcaldes impartían justicia en el municipio, mientras que los regidores y los alguaciles se encargaban del orden social y municipal. La estructura social, era, sin

\footnotetext{
${ }^{3}$ Sin embargo, tan pronto como se fundó el municipio, la iglesia se construyó en honor a Nuestra Señora de la Encarnación, y no a San Juan Bautista, como se indica en nuestra edición.
} 
duda, mucho más básica que en otros pueblos albaceteños durante la Baja Edad Media. Por ejemplo, cien años antes de la fundación de este municipio albaceteño, el orden social de la ciudad de Albacete estaba dispuesto de la siguiente forma en 1413: Lázaro Martínez de Illescas y Juan Álvarez de Pineda eran los alcaldes ordinarios; Gonzalo Fernández Piñero, Juan Alfonso de Juan Maestro y Bartolomé Rodríguez del Carralero y Alfonso Martínez de Úbeda los regidores; Pedro Márquez y Juan López de la Roda, jurados y Juan García de Denia, alguacil (Pretel Marín, 2010: p.125).

Por otra parte, Alcaraz contaba en esas mismas fechas con cinco regidores y cinco alcaldes ordinarios, cuyos aspirantes debían ser hidalgos o caballeros (Pretel Marín, 1979). Sin embargo, es poco probable que en San Juan de Villamalea se integrase en el siglo XVI la nobleza, que era prácticamente inexistente en Albacete, ya que los únicos municipios que contaban con familias nobles eran Villaverde de Guadalimar, Bienservida, Villapalacios, Carcelén, Hellín, La Roda y Jorquera (Carrilero Martínez et alii, 2014: p.361). Así, eran hidalgos que solamente representaban el 1,50\% de la población albaceteña de la época, a excepción de La Roda y Hellín, donde el porcentaje era un $4,80 \%$ y un $5,60 \%$ respectivamente.

La estructura de nuestro pueblo de 1516 era similar a la de Tarazona de la Mancha en 1565, fecha en la que se le concedió el privilegio de villazgo, en donde existían dos alcaldes - Antón de Gabaldón y Miguel Saiz Picazo -, dos alguaciles - Miguel Saiz Carretero y Francisco de Toledo - y alcaldes de hermandad - Juan de Aroca y Benito Sánchez (García Moratalla, 2005: p.55). Cabe destacar que en San Juan de Villamalea existían también un jurado y un alguacil, pero faltaban, por el contrario, otras figuras existentes en pueblos aledaños como Jorquera, tales como un escribano y un mayordomo, quien se encargaba de la administración de las cuentas de la localidad. San Juan de Villamalea tenía no más allá de cuatro o cinco familias en el año 1516, pero sabemos con seguridad que el pueblo fue creciendo poco a poco. A finales de siglo, concretamente en 1591, la población local tenía 268 habitantes, puesto que en estas fechas la 
demografía albacetense creció un 19,01\% y la española en un 25\% (Carrilero Martínez et alii, 2014: p.354).

En 1516, la estructura social quedó configurada de la siguiente forma: Martín Parra y Miguel Martínez eran los alcaldes pedáneos; Francisco de Fez y Juan Gallego, los regidores y Hernán Martín, el jurado. Se mencionan, además, en nuestro texto los primeros vecinos de la localidad, quienes fueron Pedro Monedero, Pedro Carretero, Martín Hernández, Juan Sánchez, Pedro Hernández, Benito López, Martín Martínez, Juan del Coro, Hernando de Beamud y Juan Fernandez. Así pues, los alcaldes Martín Parra y Miguel Martínez tomaron posesión de su cargo del 29 de abril de 1516 con el visto bueno de Diego López Pacheco y Portocarrero, marqués de Villena, Francisco de Verastegui, su corregidor, Pedro Goaza, su contable, y su mayordomo Álvaro de Cuéllar. Como indica el texto del asiento, Martín Parra seguía siendo alcalde de San Juan de Villamalea datado el 3 de diciembre de 1518, al igual que Hernán Martín ostentaba las responsabilidades de jurado. Parece probable, por otra parte, que Miguel Martínez fuera destituido en fechas próximas, ya que no aparece la referencia de que fuera alcalde pedáneo en estos momentos.

Francisco de Verastegui y Plazuela, quien tuvo una gran importancia para la creación de nuestro municipio, era hijo de Pedro de Verastegui y Fonseca y de Isabel de la Plazuela. Su padre ayudó al marqués de Villena en las guerras de Granada y le fue concedido el privilegio de ser alcalde de Chinchilla de Montearagón. Así pues, Francisco de Verastegui ayudó a Diego López Pacheco en la Guerra Civil entre los Reyes Católicos y el Marquesado, por lo que recibió las salinas de Fuentealbilla por sus servicios prestados (Almendros Toledo, 1985: p.24; Ayllón Gutiérrez, 1991: pp.273-281). De esta forma, los Verastegui tenían poder económico y administrativo en la zona, por lo que no ha de extrañar su participación en la fundación de la localidad de San Juan de Villamalea, y, además, obedecían a las órdenes directas del marquesado.

La construcción de la actual iglesia de Nuestra Señora de la Anunciación, por entonces dedicada a San Juan Bautista, a cargo de Juan López de Chabanieta, Adrián Martínez y Alonso de la Cárcel, fue 
una de las primeras empresas que promovió el marqués de Villena y Francisco de Verastegui, señor de las salinas de Fuentealbilla, para atraer a la población. Esperanza Blasco Liante (2017: 135), si bien no hay documentos históricos que lo confirmen, piensa que la iglesia actual se construyó sobre la de San Juan Bautista, lo cual no sería descabellado, pues parece posible que dicha ermita se encuentre en la actual sacristía del templo villamalense al ser un procedimiento habitual en aquellos años. La administración religiosa del municipio dependía del obispado de Cartagena y del arciprestazgo de Jorquera. No sabemos exactamente cuándo se pudo terminar la edificación de tan magna obra, pero sospechamos que fue hacia 1531, aunque sería reformada posteriormente en los siglos XVII y XVIII. La iglesia adquirió el grado de «parroquia» en el año 1722.

En años posteriores a la fundación, San Juan de Villamalea tuvo una vida religiosa bastante fecunda: de esta forma se construyeron un total siete ermitas, una de ellas dedicada a Santa Bárbara en la pedanía villamalense de Tamayo, otra a Nuestra Señora del Calvario, otra a San Juan Bautista , otra a Nuestra Señora de la Concepción, construida en torno a 1587; otra a San Sebastián, otra a San Agustín y otra a San Antón y a San Pedro Apóstol (Rodríguez de la Torre y Cano Valero, 1987: p.296). En la actualidad, la mayoría se han perdido o destruido y solamente se han conservado la ermita de Nuestra Señora de la Concepción, reconvertida en la Caja Rural de Villamalea, y la de San Antón, a cuatro kilómetros del municipio, siendo la única que conserva aún su carácter religioso. Por otra parte, no se constituirá una escuela de primeras letras hasta 1757, cuando el obispo Andrés Núñez Monteagudo, oriundo del lugar, la funde, además de constituir cátedras de gramática, retórica y doctrina cristiana para veinticinco alumnos (Collado Álbez, 2017: p.386).

Como es evidente, el régimen económico de San Juan de Villamalea era fundamentalmente agrícola - cultivo de la viña y del cereal -, manteniéndose en los siglos XVI y XVII, hasta que en el siglo XVIII aparecerá tímidamente el sector textil con dos fábricas de alfombras y telares de lienzos, cáñamo y lino, además de bordados 
y colchas de gorullo (Rodríguez de la Torre y Cano Valero, 1987: pp.66-67; Sánchez Ferrer y Cano Valero, 1990: pp.175-187), al igual que en Alcaraz, Ves y Almansa. Sabemos, además, que en sus orígenes, como indica el folio $300^{\mathrm{r}}$ de Capitulación, asiento y concordia acordada por el marqués de Villena con los vecinos de Villamalea (Archivo Municipal de Villamalea, ms. AMV 17/2), existía un incipiente sector ganadero lanar y cabrío. En la década de 1510 no había industria ni tejido empresarial en Villamalea, pero sí el sector agrícola y ganadero. En el siglo XIV, la ganadería era muy importante en Cenizate y en Fuentealbilla por la inseguridad social y a la falta de población, que no permitía el cultivo de los campos. No obstante, cuando se fundó nuestro pueblo, el panorama había cambiado y la agricultura era más importante que la ganadería, ya que el Marquesado de Villena impulsó el cultivo de vid y de cereal en el Estado de Jorquera (Torres Fontes, 272; Pretel Marín, 1982: p.120). Además, hemos de tener en cuenta que el viñedo se empezó a cultivar en la época debido a que en el siglo Xvi aumentó la demanda y la subida de los precios del vino, empezándose a cultivar en Yeste, La Roda, Hellín y Tobarra, además del pueblo de Jorquera, próximo a Villamalea (Carrilero Martínez et alii, 2014: p.383). Por tanto, estos factores explican por qué el pueblo tuvo, desde sus orígenes, mayor vinculación con la agricultura que con la ganadería.

La posibilidad de tener aguas manantiales subterráneas debido a su proximidad al río Cabriel propició el desarrollo de la población. En la capitulación, fechada el 29 de abril de 1516, se indica expresamente la construcción de uno o varios pozos de agua manantial y la edificación de un pilar en la fuente de las Canalejas. Gregorio López Sanz y Rafael Molina Cantos (2017: p.300) han rastreado sin éxito su posible localización, indicando que Los Cárceles (Albacete), pedanía de Villamalea, existe curiosamente «la rambla de las Canalejas». En definitiva, los vecinos de pueblos próximos percibieron la localidad como un lugar adecuado y apacible en el que vivir, frente a otros pueblos como Tarazona de la Mancha, en donde no había aguas manantiales subterráneas. En el siglo XVI era 
frecuente el aprovechamiento de las aguas del riachuelo Valdemembra para la subsistencia de los vecinos (Zarco Cuevas, 1983: p.511).

En cuanto al régimen fiscal, los villamalenses tenían que pagar la alcabala, impuesto indirecto que representaba el 10\% del valor permutado o vendido (González Arce, 2002: pp.173-190) y los pechos reales, eximiendo a los nuevos habitantes de los concejiles y de impuestos como el terrazgo el 15 de agosto de cada año, a excepción de los terratenientes vitinícolas. Por otra parte, los vecinos estaban obligados a la entrega de dos gallinas al marqués de Villena. En San Juan de Villamalea se construyó una casa tercia, que se encargaba de recoger el diezmo del pueblo y también de Cenizate. A principios del siglo XVI, como apunta José Manuel Almendros Toledo (1987: p.34), solamente existían dos más, una en Mahora y otra en Jorquera. Posteriormente, el marquesado de Villena optó conveniente crear nuevas casas tercias en los nuevos municipios Las Navas de Jorquera, Cenizate y Motilleja - para cobrar el diezmo, por lo que la población de Villamalea denunció al Marquesado en la Cancillería de Granada por los abusos fiscales a los que los vecinos se veían sometidos

Respecto a las circunstancias históricas del texto, la ratificación de los acuerdos por parte del marqués de Villena el 9 de mayo de 1531 obedece a los muchos pleitos que tuvieron lugar entre los pueblos y aldeas albaceteñas y las autoridades, que querían eliminar los beneficios del pasado con nuevas normas fiscales en la década de 1530 (Pretel Marín, 2010: p.281), continuando los abusos de la década de 1520 estudiados por José Manuel Almendros Toledo (1987: p.34). Así pues, en las décadas siguientes hubo también varios pleitos entre las localidades de la actual Manchuela, entre ellas Villamalea, contra el Marquesado de Villena, y no se sofocaron hasta finales del siglo XVIII. En este sentido, cabe destacar los siguientes pleitos de los que tenemos constancia gracias a la documentación histórica conservada: la Ejecutoria de la Real Chancillería de Granada en el pleito entre el Marqués de Villena y el concejo de Villamalea (Albacete) sobre terrazgos, dehesas, alcabalas, veintena y otros asuntos (Archivo Histórico de la Nobleza, FRIAS,C.738,D. 1-9), Pleito 
del Marqués de Villena contra los vecinos de Mahora y Villamalea (Albacete) sobre terrazgos, dehesas y otros asuntos (Archivo Histórico de la Nobleza, FRIAS, C.735,D.2-16), Pleito del cabildo contra el Marqués de Villena sobre reedificación de la torre de la iglesia de Villamalea (Archivo Histórico de la Nobleza, FRIAS, C.738, D.17-26) y Juicios de residencia de Villamalea (Archivo Histórico de la Nobleza, FRIAS, C.737, D.27-31).

La transmisión textual de Capitulación, asiento y concordia acordada por el marqués de Villena con los vecinos de Villamalea es bastante compleja. En primer lugar, el texto ideal $(\Omega)$ da lugar al arquetípico $(\chi)$, y este, a su vez, en el manuscrito autógrafo perdido de la capitulación del marqués de Villena de abril de 1516, al que llamaremos $C_{1}$. Esta edición fue refundida dos años después en el texto del asiento $(A)$ del 3 de diciembre de $1518 \mathrm{y}$, de nuevo, ambos textos se reescribieron en la concordia en $1531\left(C_{2}\right)$. En principio, no ha sido posible localizar el texto $C_{2}$, que posiblemente se haya perdido. Sin embargo, la edición $C_{2}$ da lugar a dos copias manuscritas apógrafas conservadas, por un lado, en el Archivo Municipal de Villamalea con signatura $A M V-17 / 2$, al que llamaremos $V$, y, por otro, en el Archivo Histórico de la Nobleza (Toledo) con signatura FRIAS, C.738,D.1-9, de datación posterior entre 1567 y 1597, al que llamaremos $T$ :

Ejecutoria de la Real Chancillería de Granada en el pleito entre el Marqués de Villena y el concejo de Villamalea (Albacete) sobre terrazgos, dehesas, alcabalas, veintena $y$ otros asuntos, ff., $11^{\mathrm{v}}-19^{\mathrm{v}}$, letra del siglo XVI.

Archivo Municipal de Villamalea, $A M V-17 / 2$.

Ejecutoria de la Real Chancillería de Granada en el pleito entre el Marqués de Villena y el concejo de Villamalea (Albacete) sobre terrazgos, dehesas, alcabalas, veintena $y$ otros asuntos, ff. $297^{\mathrm{r}}-304^{\mathrm{v}}$, letra del siglo XVI.

Archivo Histórico de la Nobleza, FRIAS,C.738,D.1-9. 


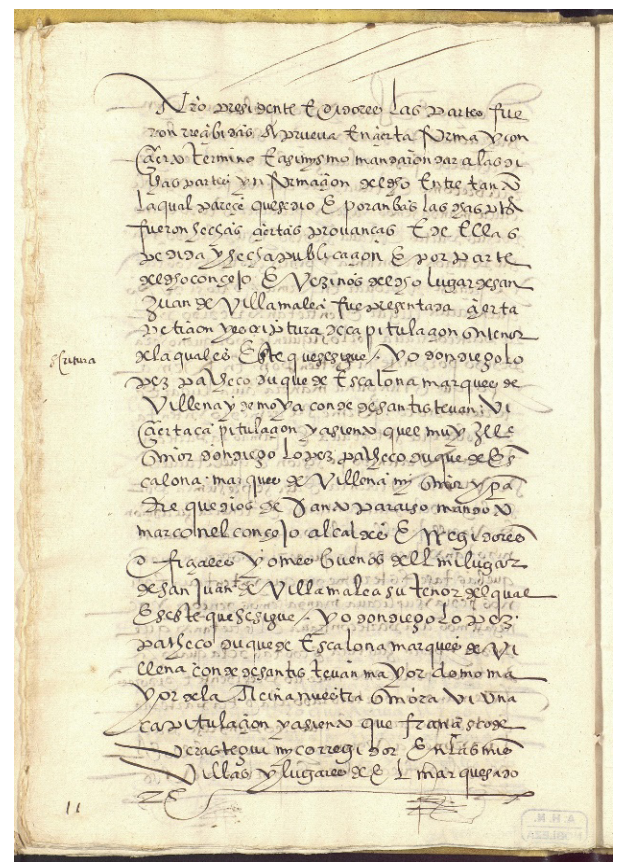

Figura II. Inicio de la Capitulación, asiento y concordia acordada por el marqués de Villena con los vecinos de Villamalea en la edición $T$.

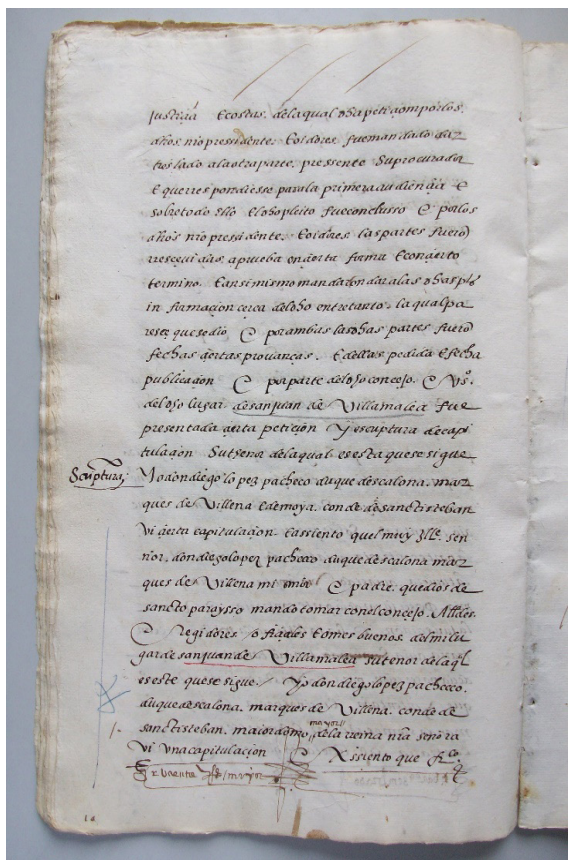

Figura III. Inicio de la Capitulación, asiento y concordia acordada por el marqués de Villena con los vecinos de Villamalea en la edición $V$.

La edición $V$ es, sin duda, posterior a la $T$, ya que encontramos tachaduras y frases superpuestas que denotan olvidos del escribano, como mostramos a continuación. Es destacable que en la figura V se produce una lectio errónea, ya que se tacha el verbo que figuraría, en principio, en la edición $C_{2}$ y que está presente en la $T$ :

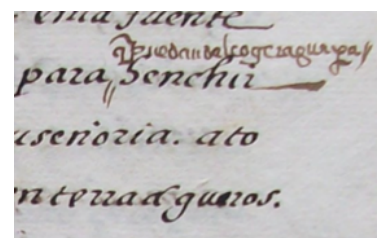

Figura IV. Olvido del copista en el folio $199 \mathrm{v}$ de la edición $V$.

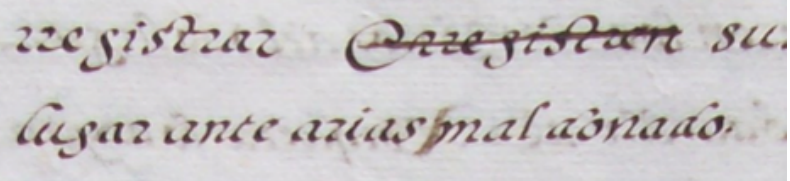

Figura V. Lectio errónea en el folio 301r de la edición $V$.

Proponemos, por tanto, el siguiente stemma codicum para nuestro texto: 

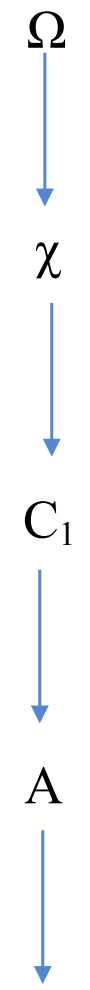

$\mathrm{C}_{2}$
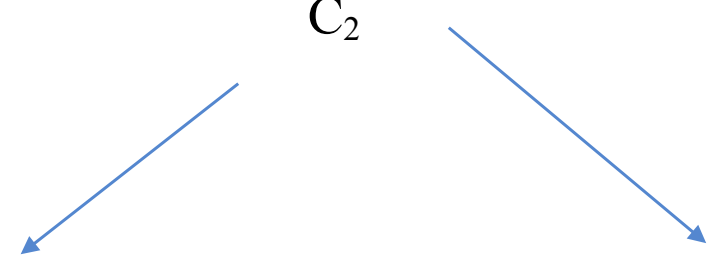

$\mathrm{V}$

Seguiremos los siguientes criterios de edición:

1. La cursiva se utiliza para palabras extranjeras y títulos de obras. Por tanto, resolvemos las abreviaturas sin dejar constancia de ello.

2. No respetamos los casos de variatio o vacilación gráfica (ciencia/sciencia, mientra/mientre, etc) ni los casos de vacilación tímbrica de las vocales. 
3. Resolvemos por «y» el signo tironiano y regularizamos según su valor vocálico o consonántico $u / v, i / y / j$.

4. La vacilación de los grupos $m p$ y $m b$ se respeta y se resuelve la abreviatura de la nasal en $m$.

5. No conservamos la ç ante $i$ y $e$ por su impertinencia fonológica. Tampoco conservamos el dígrafo $s c ̧$ - ante $i$ y $e$ (fallesçe $=$ fallece), puesto que nunca representó en castellano dos fonemas (Álvarez Rodríguez, 2006: pp.351-376).

6. Restituimos sistemáticamente la $h$ en todas las formas de haber $(a y=h a y)$ y en las interjecciones $(O=O h)$.

7. Simplificamos las consonantes dobles según el uso actual.

8. No conservamos las grafías de las sibilantes medievales, ni cultismos gráficos (Christo, Ihesús, Joseph) y la grafía q en palabras como quanto, qüento. Tampoco nos servimos del apóstrofo para indicar el apócope (díxol').

9. En la puntuación y acentuación del texto, nos atenemos en principio a la actual normativa ortográfica, con algunas licencias usadas habitualmente por los editores de textos antiguos, con el fin de no desorientar al lector: por ejemplo, el uso de la tilde para distinguir formas hoy en desuso (nós/nos, vos/vós), en razón de la tonicidad; el uso de la tilde en como cuando equivale a un que introductor de una oración subordinada enunciativa, tenga o no matiz modal (Ahora veréis cómo no me quedo atrás).

10. Los textos en estilo directo van entrecomillados.

11. Utilizamos los corchetes [] para dejar constancia de errores, lagunas y olvidos morfosintácticos por parte de los copistas. 


\section{EDICIÓN CRÍTICA}

[El MARQUÉS DE VILLENA, DON DIEGo LóPEZ PACHECO, RATIFICA LA CAPITULACIÓN, EL ASIENTO, ACORDADOS POR SU PADRE Y POR EL CONCEJO, ALCALDES, REGIDORES, OFICIALES Y HOMBRES BUENOS DEL LUGAR DE SAN JUAN DE VILLAMALEA EN ALARCÓN EL 9 DE MAYO DE 1531].

Yo, don Diego López Pacheco [y Enríquez] ${ }^{4}$, duque de Escalona ${ }^{5}$, marqués de Villena y de Moya, conde de san Esteban de Gormaz ${ }^{6}$, vi cierta capitulación y asiento [en] aquel muy ilustre señor, don Diego López Pacheco [y Portocarrero], duque de Escalona y marqués de Villena, mi señor y padre, que Dios de santo paraíso mandó [a] tomar el concejo, alcaldes, regidores, oficiales y hombres buenos ${ }^{7}$ de mi lugar de San Juan de Villamalea, su tenor de la cual es este que se sigue:

[CAPITULACIÓN DEL MARQUÉS DE VILLENA, DIEGO LÓPEZ PACHECO Y PORTOCARRERO, Y POR EL CONCEJO, ALCALDES, REGIDORES, OFICIALES Y HOMBRES BUENOS DEL LUGAR DE SAN JUAN DE VILLAMALEA, EL MARTES 29 DE ABRIL DE 1516].

\footnotetext{
${ }^{4}$ Diego López Pacheco y Enríquez (1503-1556), III marqués de Villena, III duque de Escalona, III conde de Xiquena, VI conde de san Esteban de Gormaz, señor de Belmonte y marqués consorte de Moya, hijo de Diego López Pachecho y Portocarrero (1447-1529) y Juana Enríquez de Velasco, ratifica la capitulación, asiento y concordia, firmada el martes 29 de abril de 1516 en Villamalea (Albacete) y redactada el 3 de diciembre de 1518 en Escalona.

${ }^{5}$ Municipio de la provincia de Toledo. El ducado de Escalona fue creado por Enrique IV de Castilla (1425-1474) en 1492 a favor de Juan Pacheco. Fernando VI de España (1713-1759) lo elevó en 1750 a categoría de «Grande de España».

${ }^{6}$ San Esteban de Gormaz es un municipio de la provincia de Soria. El 13 de junio de 1423, Juan II de Castilla (1405-1454) le concedió el condado de San Esteban de Gormaz a su valido Álvaro de Luna (1390-1453).

${ }^{7}$ Durante la Edad Media, en los reinos de Castilla y León, se entendía por «hombres buenos», «omes buenos» a los habitantes que alcanzaban un alto grado de riqueza en un lugar y podían participar en el concejo cerrado del municipio. Eran nombrados por la Corona y desempeñaban tareas administrativas y, ocasionalmente, judiciales.
} 


\section{[Preámbulo]}

Yo, don Diego López Pacheco [y Portocarrero] ${ }^{8}$, duque de Escalona, marqués de Villena, conde de san Esteban de Gormaz [y] mayordomo mayor de la Reina Nuestra Señora, vi que Francisco de Verastegui, mi corregidor había realizado una capitulación y asiento en las villas y lugares del marquesado; [y que] Pedro de Goaza, mi contable, y Alonso de Cuéllar, mi mayordomo, [también] en las villas de Alcalá del Río ${ }^{9}$ y Jorquera con los vecinos que viven en San Juan 10 de Villamalea, lugar y jurisdicción de mi villa de Jorquera, hicieron el tenor de la cual es este que se sigue:

\section{[Apartado I]}

En Fuentealbilla, lugar y jurisdicción de la villa de Jorquera, [a] martes veintinueve días del mes de abril del año del nacimiento de nuestro señor Jesucristo de 1516, nos juntamos el señor Francisco de Verastegui, corregidor y justicia mayor de las villas y lugares del marquesado de Villena, el contable Pedro de Goaza y Alonso de Cúellar, mayordomo de su señoría, por virtud de una provisión del señor marqués, en que, en efecto, por ella nos da comisión que asentemos y capitulemos con los del lugar de san Juan, término y jurisdicción de la villa de Jorquera todas las cosas tocantes a la población, derechos, servidumbres, exenciones, ordenanzas y todas las otras cosas del dicho lugar y vecinos del que ahora son, o serán de aquí [en] adelante, y con los susodichos se juntaron para ello para eso y en nombre del dicho concejo del dicho lugar de san Juan, y por todos los que después vinieren a poblar en el dicho lugar: Martín

\footnotetext{
${ }^{8}$ Firma Diego López Pacheco y Portocarrero (1447-1529), padre de Diego López Pacheco y Enríquez (1503-1556).

${ }^{9}$ Se refiere a la actual Alcalá del Júcar, conocida por entonces como «Alcalá del Río», como consta en las Relaciones topográficas de Felipe II (Carrilero Martínez et alii, 2014).
} 
Parra y Miguel Martínez, alcaldes; Francisco de Fez y Juan Gallego, regidores; Hernán Martínez, jurado, oficiales del dicho lugar; Pedro Monedero, Pedro Carretero, Martín Hernández, Juan Sánchez, Pedro Fernández, Benito López, Martín Martínez, Juan del Toro, Hernando de Beamud y Juan Hernández, todos los vecinos del dicho lugar concertamos y asentamos los capítulos siguientes:

30 Primeramente: concertamos y asentamos que en el dicho lugar de San Juan [de Villamalea] se haga una iglesia ${ }^{10}$ y que ahora [en el] presente su señoría dé para ella un cáliz con su patena de plata con dos vestimentas cumplidas, un frontal y un misal del obispado de Cartagena y que su señoría dará después que se haya hecho un tercio en el dicho lugar, la cual ha de hacer su señoría el rediezmo del pan de los vecinos del dicho lugar, todo el tiempo que la obra de la dicha iglesia dure, [que] ha de ser advocación de la Encarnación. Y también concertamos que en el dicho lugar haya dos alcaldes pedáneos ${ }^{11}$ los cuales puedan juzgar hasta en doscientos maravedís y en todo lo demás hacer todo lo demás que los alcaldes pedáneos son obligados, reconociendo su superioridad a la villa de Jorquera y que haya dos regidores, un aguacil y un jurado, los cuales por suerte, se elijan el día de san Miguel $^{12}$ de septiembre de cada año y que por este presente año hasta el dicho día de san Miguel tengan los que tienen. Y también que su señoría procure de hacer un pozo de agua manantial y [alguno] más, si fuese necesario. Y también que su señoría les ha de mandar hacer un pilar en la Fuente de

${ }^{10}$ La iglesia que se construyó se conserva en la actualidad y, según Blasco Liante (2017: p.136), se acabó en 1531. Recordemos que estas líneas se redactaron el martes 29 de abril de 1516 y, por tanto, no se había construido aún. Gran parte del patrimonio histórico-artístico del pueblo de Villamalea que se ha perdido pudo alzarse en estas fechas. Me refiero, por supuesto, a las ermitas de San Sebastián, de San Agustín, de Nuestra Señora del Calvario y de Santa Bárbara.

${ }^{11}$ Martín Parra y Miguel Martínez, presentes en este texto, serán los primeros alcaldes pedáneos de san Juan de Villamalea.

${ }^{12}$ Los cargos públicos se renovaban el día 29 de septiembre por la ordenanza de fueros (Rouoil, 1968: p.293), al igual que el resto de municipios albaceteños. 
las Canalejas ${ }^{13}$ donde se recoja agua para que puedan para llenar brevemente sus tinajas. También que su señoría a todos los vecinos del dicho lugar que fueran terratenientes, les hace merced que sean francos de alcabala de todo lo que vendieran de su labranza, crianza y tracto en todos los términos de Jorquera, excepto los que tuvieren oficios públicos de consejo, así como carnicerías, tabernas, tienda[s] y otros oficios públicos de consejo que han de pagar alcabala; los que de fuera vinieren a vender cualquier cosa 55 al dicho lugar y no sean tengan que pagar veintena y así mismo sean francos de taja y veinte y los dichos terratenientes que ahora viven en el dicho lugar y los que a él viniesen de aquí [en] adelante tanto que sean terratenientes para siempre jamás. También que los susodichos terratenientes puedan gozar y gocen y [puedan] usar y usen de los términos de Jorquera [para] labrar y cortar el pacer y beber las aguas y todas las otras cosas, y privilegios de la dicha villa, así como los mismos vecinos de ella sin perjuicio de 60 las dehesas, que en el dicho término de Jorquera hay. También que los dichos terratenientes y otros vecinos de dicho lugar no tengan que contribuir ni pagar a la dicha villa de Jorquera por los pechos concejiles de ella, sino diez maravedíes cada vecino en cada año y que en los pechos reales hayan de contribuir como vecinos con ellos, como les cupiese. También que hasta cinco oficiales en el dicho lugar hubiere; conviene a saber un sastre, un zapatero, [un] tejedor, [un] herrero, y un barbero. No obstante, que no sabían que no tengan 65 que pagar alcabala y gocen de todas las libertades y franquezas que gozan los vecinos terratenientes del dicho lugar. También que su señoría les dará ordenanzas por donde se sigan. También que las tierras que los terratenientes que ahora hay o hubiere de aquí [en] adelante las puedan dejar holgar seis años cuando estuvieren cansadas para que descansen y que en este tiempo ninguno las

${ }^{13}$ López Sanz y Molina Cantos (2017: p.300) han estudiado las fuentes actuales de Villamalea. No obstante, no encuentro ninguna fuente en la actualidad, ni por documentación, ni fuentes orales que se llame así, pero sí la Rambla de las Canalejas, ubicada en la pedanía de Los Cárceles, a unos cinco kilómetros de Villamalea. 
pueda tomar ni ocupar contando los dichos seis años desde que las segaron y alcanzaron los frutos de ellas hasta ser cumplidos, y [hasta que no] hayan pasado los dichos seis años no las vuelvan a labrar y sembrar que otros o cualquier o cualesquiera terrateniente o terratenientes del dicho lugar las puedan tomar y labrar con tanto que el que así dejare la dicha tierra para dejarla holgar, [hasta que] la tenga que registrar el escribano del consejo del dicho lugar en el libro del dicho consejo, desde el día que alzare el esquilmo de ella hasta el final del mes de mayo siguiente, asentando y poniendo en el dicho libro [de] donde es la dicha tierra y que almohadas cabe y que aledaños tiene. Y si dentro del dicho término no la asentare en el dicho libro de concejo ante el dicho escribano cualquier otro terrateniente la puede tomar y labrar pasado un año y día después que así viviere alzado el esquilmo de ella no embargante que hasta aquí estaba en costumbre aquel que sembraba un atierra y luego 80 no la volvía a barbechar después de alzado el esquilmo de ella para sembrar otro año siguiente otro cualquiera terrateniente se la podía volver a tomar y barbecharla y sembrarla. También que se les dará dehesa de boalaje, por la cual nosotros, los susodichos, corregidor Francisco de Vrastegui, contador Pedro de Goaza y Alonso de Cuéllar les será señalada lo que los dichos concejos, vecinos y moradores del dicho lugar de san Juan tengan que pagar al marqués lo siguiente:

85 Primeramente: Que tengan que pagar y paguen los susodichos terratenientes que ahora viven el he dicho lugar y los otros terratenientes se vinieren a vivir para siempre jamás de terrazgo ${ }^{14}$, de todo pan y otras cosas que cogieran y tuvieran en los dichos términos de Jorquera de doce fanegas ${ }^{15}$, una y doce cosas una, de los ganados que traigan en los dichos términos; tengan que pagar y paguen su derecho como hasta aquí han pagado y pagan los vecinos

${ }^{14}$ El impuesto de terrazgo consiste en que el labrador de una tierra determinada paga una determinada cantidad a su dueño.

${ }^{15}$ Medida de capacidad para áridas que, según el marco de Castilla, tiene 12 celemines y equivale a 55,5 litros, pero es muy variable según las diversas regiones de España (DRAE: en línea). 
de Mahora, en cada año de cada millar de ganado lanar, nueve reses de cabrío y más de cada hato ${ }^{16}$ que tuviera cada vecino una res de borra, otra de asadura, otra de reinado y no paguen puente ${ }^{17}$, aunque la pasen con sus ganados, ni de otra manera, que tengan que pagar ocho días antes de san Andrés ${ }^{18}$, y ocho días después cada año, o a este tiempo sea obligado el dicho señor marqués de mandarlo [a] recibir y los años [siguientes] los terratenientes no tengan que pagar, más el dicho ganado a este término se avengan al precio que lo tengan que pagar y lo paguen al término que con ellos se aviniere la persona que en nombre de su señoría la tenga que cobrar. Y el terrazgo tengan que pagar y paguen por el día de santa María de Agosto de cada año puesto en la casa de la tercia o en la casa del dicho señor marqués tuviera en el dicho lugar para poner 105 el dicho pan o antes si se cogiere el dicho pan. Y de las otras cosas que se cogieran o tuvieran en el dicho término se pagaran cuando se cogieren o tuvieran, excepto de las viñas que no paguen terrazgo ninguno. También que todo el pan y otras cosas de la labranza que cogieren los vecinos del dicho lugar en los términos de la dicha villa de Jorquera ${ }^{19}$ lo tengan que traer y traigan a despajar al dicho lugar [de] san Juan. También cada vecino de los que ahora viven o viviesen en el dicho lugar de aquí [en] adelante tengan que pagar

110 y paguen al dicho señor marqués por nombre de señorío en cada año un par de gallinas el día de Navidad de cada año. También que los que se vinieren a vivir al dicho lugar de aquí [en] adelante para ser terratenientes les tengan que dar sitios para hacer casas, las que sean necesarias, y no les tengan que llevar ni lleven los que ahora viven en el dicho lugar maravedís y otras cosas, sino que se las den, sin dinero para tener los sitios que se tengan que dar a los que así

\footnotetext{
${ }^{16}$ Porción de ganado mayor o menor ( $D R A E$ : en línea).

${ }^{17}$ Se refiere al impuesto indirecto de pontazgo, frecuente en los reinos de Castilla y León, que se pagaba al pisar los terrenos, fincas y otros territorios de un determinado noble, en este caso, el marqués de Villena.

${ }^{18}$ La festividad del apóstol Andrés se celebra el 30 de noviembre.

${ }^{19}$ Aquí, efectivamente, es el pueblo de Jorquera, y no sus alrededores.
} 
115 se viniesen, diputen a una persona los dichos terratenientes y el dicho señor marqués otra para darles, porque cada terratenientes que viniere tenga que hacer [una] casa en [la] que viva. También que los que ahora viven en el dicho lugar y los que de aquí [en] adelante se vinieran a vivir a él que así fuesen terratenientes que tengan que registrar y registren sus ganados en el dicho lugar ante

120 Arias Maldonado, escribano de Jorquera, o ante él tuviera puesto su lugarteniente, en el dicho lugar hasta cuatro días después de san Pedro y san Pablo cada, o antes si antes quisiere y que no caigan en pena ninguna por no registrarla antes que el dicho término y que tengan que pagar [a] Arias Maldonado, escribano de Jorquera, que es el escribano de las rentas que fuera después de él, veinte 125 maravedís de cada hato de derecho. También que todos los vecinos del dicho lugar tengan que poner y pongan viñas en la parte que les sea señalada y cada uno que la labre con un par de mulas o de bueyes tenga que poner dos mil vides [por] lo menos, y más si más pudiera o quisiera de las cuales no tengan que pagar terrazgo, como ya se ha dicho. También que por cuanto ahora los que viven en el dicho lugar tienen todas las tierras que están más cerca del lugar y los que a él nuevamente han venido y vienen a ser terratenientes tienen necesidad, a lo menos cada uno de ellos hasta en número de cien vecinos dos quiñones para cada año y vez para cebada para cada uno de ellos, diez almudadas concertaron y asentaron que se hayan de hacer y hagan doscientos quiñones alrededor del dicho lugar, en que haya las dichas diez mil almudadas en cada año para cada uno dos quiñones y porque ahora al presente no hay tantos vecinos en

135 que se repartan entre todos los que ahora hay los dichos doscientos quiñones. Y, cuando algún terrateniente de nuevo viniera, que se le tenga que dar dos quiñones para [una] vez [al] año y [que] se tomen del que más quiñones tuviera y si tuvieran igualmente que tengan que echar suertes que lo deje al que tuviera suerte. Y cuando los dichos quiñones se amojonasen, los repartan por su suerte para hacerlos amojonar tengan que poner los susodichos vecinos del lugar una persona y por parte del dicho señor marqués se ponga 
140 otra y aquello se asiente en el libro del dicho concejo señalando los que quedan a los vecinos que ahora hay en el dicho lugar y los que demasiados de los dos, que cada una ha de tener queden a cada uno porque se sepan en cuyo poder quedan para los que han de venir y de ello se dé a cada uno de los que viniesen a ser terratenientes dos quiñones como dicho, lo cual todo susodicho. Nosotros, los

145 [suso]dichos, corregidor Francisco de Verastegui, Pedro de Goaza y Alonso de Cuéllar, decimos en nombre de su señoría y por virtud de la comisión, a nosotros otros, por su señoría dada, que se guardara y cumpliera todo lo dicho [anteriormente], como en este asiento y capitulación se contiene, y nosotros, los dichos Martín Parra, Miguel Martínez, alcaldes; Francisco de Fez y Juan Gallego, regidores;

150 Hernán Martín, jurado, oficiales del dicho lugar; Pedro Monedero, Pedro Carretero, Martín Hernández, Juan Sánchez, Pedro Hernández, Benito López, Martín Martínez, Juan del Coro, Hernando de Beamud y Juan Fernández, todos los vecinos del dicho lugar por nosotros y por todos los vecinos del dicho lugar que ahora somos y a los que serán de aquí [en] adelante para siempre jamás, nosotros obligamos a nosotros y a nuestros bienes y a los bienes de los otros vecinos y moradores del dicho lugar [en el] que ahora están y a los que serán de aquí [en] adelante que tenemos, mantenemos, cumpliremos y pagaremos todo lo contenido en el dicho asiento y capitulación y contra ello ni contra parte de ello nosotros ni alguno de nosotros, ni de los que después viniesen a ser vecinos terratenientes del dicho lugar, no iremos ni veremos ni lo contradiremos ni contradirán ahora ni en tiempo alguno que sea, su obligación de nuestras personas y bienes y de las personas y bienes de los que [en] adelante viniesen a ser vecinos terratenientes del dicho lugar de lo cual todo susodicho a más las dichas partes otorgamos dos escrituras de un tenor, tal la una como la otra para cada una de las dichas partes la suya firmamos de nuestros nombres, y las otorgamos ante el escribano y testigos yuso escritos el dicho día [del] mes y [del] año susodicho. 
[REDACCIÓN DEL ASIENTO EL 3 DE DICIEMBRE DE 1518 EN LOS ALCÁZARES DE ESCALONA, PREVIA FIRMA DE LOS VECINOS DE VILLAMALEA EL 29 DE ABRIL DE 1516] ${ }^{20}$.

165 Francisco de Verastegui, Pedro de Goaza, Alonso de Cuéllar; Martín Parra, alcalde; Fernán Martínez, jurado; Gonzalo Ruiz, testigos que estuvieron presentes al otorgamiento de todo lo dicho [anteriormente] y vieron aquí firmar sus nombres a los dichos señores y a los del concejo del dicho lugar que sabían escribir y por los que no sabían Gonzalo Ruiz, vecino de la villa de Jorquera,

170 Álvaro Calderón y Diego de Cañabate, vecinos de Jorquera y Alcalá, escribano del dicho lugar, Fuentealbilla, fui presente en uno con los dichos testigos a todo lo que se ha dicho, y al otorgamiento de ello, vi aquí firmar sus nombres y de pedimiento de los dichos señores y consejo, es tal [la] escritura que hice escribir y, por tanto, en testimonio de verdad, hice aquí este acostumbrado signo mío a tal, en testimonio de verdad, Rodrigo de Ávila, escribano.

\section{[Apartado II]}

170 Y así por mi visto la dicha capitulación y el pedimiento que por parte del dicho concejo y hombres buenos que por parte del dicho lugar de San Juan me fue hecho para que la mandase confirmar, aprobar y cumplir, como en ella se contiene, y los [suso]dichos, mi corregidor, [mi] contador y [mi] mayordomo, la hicieron y [la] otorgaron. Digo que estoy contento y me place de hacerla guardar y cumplir, ahora y en todo tiempo para siempre jamás sin falta ninguna ni alguna y que la confirmo, la loo y [la] apruebo y la tengo

175 por buena, y cumpliéndola mando a mis contadores o a cualquiera de ellos que la vean y si alguna cosa de lo que a mí toca e incumbe de cumplir falta y no estar hecha ni cumplida, os doy mis cartas y mandamientos, cuales y cuantos convengan y [que] sean necesarios para el cumplimiento de lo dicho [anteriormente] y mando a mi muy amado hijo, don Diego López Pacheco, conde de san Esteban de

\footnotetext{
${ }^{20}$ Vid. nota 7, en donde explico la relación del marqués de Villena con el condado de Escalona
} 
180 Gormaz, y a los corregidores y alcaldes y otras justicias que ahora son y serán de aquí [en] adelante, en la villa de Jorquera que así lo guarden y cumplan y hagan guardar y cumplir, como en la dicha capitulación se contiene y contra el tenor y forma de ella ni parte de ella no os vayan ni pasen, ni consientan ir ni pasar en tiempo 185 alguno, ni por laguna manera bajo pena de diez mil maravedís para mi cámara al que lo contrario hiciera. Redactada en mis alcázares de Escalona a tres días del mes de diciembre del año del nacimiento de nuestro salvador hijo Jesucristo de mil y quinientos dieciocho,

$$
\text { el Marqués }{ }^{21} \text {. }
$$

Yo, Sancho Fernández, secretario del duque, marqués y conde, mi señor, la hice escribir por su mandado. El licenciado Hucero, registrador Pedro Gutiérrez, concejo, justicia y regidores, caballeros, escuderos, oficiales y hombres buenos, mayordomos, receptores, arrendadores, fieles, cogedores y cualquier persona, en esta carta del marqués, mi señor, contenidas, vedla, guardadla, cumplidla y hacedla, guardar y cumplir en todo y por todo según en ella se contiene bajo las penas [que] en ellas contiendas y de diez mil maravedís para la cámara de su señoría,

Pedro Núñez.

[El marqués De VILlena, don Diego López PaCheco, Ratifica LA CONCORDIA, ACORDADA POR SU PADRE Y POR EL CONCEJO, ALCALDES, REGIDORES, OFICIALES Y HOMBRES BUENOS DEL LUGAR DE SAN JUAN DE VILLAMALEA CON FECHA DE 29 DE ABRIL DE 1516, EN ALARCÓN EL 9 DE MAYO DE 1531.].

$\mathrm{Y}$ ahora por parte del concejo, alcaldes, regidores y hombres buenos del dicho lugar de san Juan de Villamalea, me fue suplicado $\mathrm{y}$ pedido por merced [que] les mandase confirmar y guardar la dicha capitulación y asiento por la forma en ella contenida y yo lo tuve por bien. Por tanto, la presente la apruebo, confirmo y

${ }^{21}$ Se refiere a Diego López Pacheco y Portocarrero (1447-1529). 
mando que les sea guardada y cumplida al dicho concejo y [que] a los vecinos y moradores del dicho lugar, que ahora son, o por 200 todo tiempo sean, por la forma en ella contenida, y contra el tenor de aquella, no les vayan ni pasen en tiempo alguno, ni por laguna manera para siempre jamás. Y mando a cualquiera [de] mis justicias de mi villa de Jorquera, que ahora son o por todo tiempo sean, que se la hagan así tener, guardar y cumplir bajo las penas [que] en ellas contenidas en firmeza de lo cual le mande dar esta mi carta de 205 confirmación y aprobación en la manera que dicha es firmada de mi nombre y sellada con el sello de mis armas y refrendada [por] Pedro Gutiérrez, mi tesorero y secretario. Redactada en la villa de Alarcón, a nueve días del mes de mayo, año del señor de mil quinientos treinta y uno.

El marqués, duque y yo Pedro Gutiérrez, tesorero y secretario del duque, marqués, conde, mi señor, la hice escribir por su mandato.

\section{APARATO DE VARIANTES}

\section{SigLAS UTILIZADAS EN EL APARATO DE VARIANTES}

V

Ejecutoria de la Real Chancillería de Granada en el pleito entre el Marqués de Villena y el concejo de Villamalea (Albacete) sobre terrazgos, dehesas, alcabalas, veintena y otros asuntos, ff., $11^{\mathrm{v}}-19^{\mathrm{v}}$, letra del siglo XVI.

Archivo Municipal de Villamalea, $A M V-17 / 2$.

$T$

Ejecutoria de la Real Chancillería de Granada en el pleito entre el Marqués de Villena y el concejo de Villamalea (Albacete) sobre terrazgos, dehesas, alcabalas, veintena y otros asuntos, ff. $297^{\mathrm{r}}-304^{\mathrm{v}}$, letra del siglo XVI.

Archivo Histórico de la Nobleza, FRIAS,C.738,D.1-9. 
5 el concejo $T$ con el concejo $V$

17 marqués $T$ marquesado $V$

38 reconociendo $T$ reconosaendo $V$ Errata

69 dichos $T$ otros $V$

116 registren $T$ Tachado en $V$

146 Pedro $T$ Pero $V$

188 mandado $T$ mandato $V$ 


\section{REFERENCIAS BIBLIOGRÁFICAS}

ALMENDROS TOLEDO, J. A. (2000). Configuración del término de Jorquera por un privilegio alfonsino. En Aurelio Pretel Marín (coord.), II Congreso de Historia de Albacete: del 22 al 25 de noviembre de 2002, (2) (pp. 57-62). Instituto de Estudios Albacetenses «Don Juan Manuel».

ALMENDROS TOLEDO, J. A. (1987). Apuntes para el estudio de la extinción del Señorío de Jorquera. En Congreso de Historia del Señorío de Villena, Albacete, 23-26 de octubre de 1986 (pp. 2744). Instituto de Estudios Albacetenses «Don Juan Manuel».

ALMENDROS TOLEDO, J. A. (1985). Algunas notas sobre las salinas de Fuentealbilla. Al-Basit: Revista de estudios albacetenses (17), 19-62.

ÁLVAREZ RODRÍGUEZ, A. (2006). Los resultados hispanos del grupo latino sc ante vocal palatal. Révue de Lingüistique Romane (70), 351-376.

AYLLÓN GUTIÉRREZ, C. (1991). Las salinas de Fuentealbilla y el abastecimiento de sal en la comarca albacetense durante la Baja Edad Media. Al-Basit: Revista de estudios albacetenses (28), 273-281.

BLASCO LIANTE, E. (2017). Patrimonio histórico-artístico cultural (V Centenario de Villamalea). En Cano Valero J. (coord.), ViIlamalea: retazos de historia y de la vida de sus gentes (pp. 129-192). Instituto de Estudios Albacetenses «Don Juan Manuel».

BLECUA PERDICES, L. A. (1983). Manual de crítica textual. Castalia.

CANDEL CRESPO, F. (1993). Obispos fulgentinos. Scripta fulgentina: revista de Teología y Humanidades, (5-6), 123-169

CARRILERO MARTÍNEZ, R. (1997a). Ordenanzas de Albacete en el siglo XVI: edición crítica y estudio documental. Instituto de Estudios Albacetenses «Don Juan Manuel». 
CARRILERO MARTÍNEZ, R. (1997b). Paleografía y diplomática albacetenses: iniciación al conocimiento de los fondos documentales del Archivo Histórico Provincial de Albacete (siglos XIII$X V I I)$. Instituto de Estudios Albacetenses «Don Juan Manuel».

CARRILERO MARTÍNEZ, R. (2000). Carlos V y Albacete: colección documental del emperador en el Archivo Histórico Provincial. Instituto de Estudios Albacetenses «Don Juan Manuel».

CARRILERO MARTÍNEZ, R. (2002). Colección documental albacetense de la reina doña Juana (1505-1519). Instituto de Estudios Albacetenses «Don Juan Manuel».

CARRILERO MARTÍNEZ, R. (2002). La emperatriz Isabel de Portugal, señora de Albacete y de Alcaraz (1526-1539): estudio histórico-documental. Instituto de Estudios Albacetenses «Don Juan Manuel».

CARRILERO MARTínEZ, R. (2004). Los Reyes Católicos en la documentación albacetense (1476-1504). Instituto de Estudios Albacetenses «Don Juan Manuel».

CARRILERO MARTÍNEZ, R et alii (2014). Pueblos de la provincia de Albacete en las relaciones topográficas de Felipe II (estudio documental, filológico e histórico). Instituto de Estudios Albacetenses «Don Juan Manuel».

COLLADO ÁLBEZ, M. (2017). Algunos personajes destacados de Villamalea. En Cano Valero, J. (coord.), Villamalea: retazos de historia y de la vida de sus gentes (pp. 383-514). Instituto de Estudios Albacetenses «Don Juan Manuel».

DAIN, A. (1975). Les manuscrits. Les Belles Lettres.

GARCÍA MORATALLA, P. J. (2005). Tarazona del Marquesado de Villena: concejo y gobierno municipal tras el privilegio de villazgo de 1564. Instituto de Estudios Albacetenses «Don Juan Manuel».

GONZÁLEZ ARCE, J. D. (2002). La fiscalidad del señorío de Villena en la Baja Edad Media. Instituto de Estudios Albacetenses «Don Juan Manuel». 
LÓPEZ SANZ, G.; MOLINA CANTOS, R. y M. MELGOSO NAVARRO (2017). Tollos de Villamalea. En Cano Valero, J. (coord.), Villamalea: retazos de historia y de la vida de sus gentes (pp. 307348). Instituto de Estudios Albacetenses «Don Juan Manuel». LÓPEZ SANZ, G. y R. MOLINA CANTOS (2017). Fuentes de Villamalea. En Cano Valero, J. (coord.), Villamalea: retazos de historia y de la vida de sus gentes (pp. 279-306). Instituto de Estudios Albacetenses «Don Juan Manuel».

PÉREZ PRIEGO, M. A. (1997). La edición de textos. Síntesis.

POCKLINGTON, R. (2010). Toponimia ibérica, latina y árabe de la provincia de Albacete. Al-Basit: Revista de estudios albacetenses, (55), 111-167.

PRETEL MARÍN, A. (2010). La villa de Albacete en la Baja Edad Media. Instituto de Estudios Albacetenses «Don Juan Manuel».

PRETEL MARÍN, A. (1982). Don Juan Manuel, señor de la llanura (repoblación y gobierno de la Mancha albacetense en la primera mitad del siglo XIV. Instituto de Estudios Albacetenses «Don Juan Manuel».

PRETEL MARÍN, A. (1979). La integración de un municipio medieval en el Estado autoritario de los Reyes Católicos (La ciudad de Alcaraz, 1475-1525). Instituto de Estudios Albacetenses «Don Juan Manuel».

RODRÍGUEZ DE LA TORRE, F. y J. CANO VALERO (1987). Relaciones geográfico-históricas de Albacete (1786-1789) de Tomás López. Instituto de Estudios Albacetenses «Don Juan Manuel».

ROUOIL, J. (1968). Les fueros d'Alcaraz et d'Alarcon. Libraire Klinckiesck.

SÁNCHEZ FERRER, J. y J. CANO VALERO (1990). Descentralización de la manufactura textil en Villamalea a principios del siglo XVII. Anales del Centro Asociado de Albacete (10), 175-187. 
TORRES FONTES, J. (1953). La conquistando del Marquesado de Villena en el reinado de los Reyes Católicos. Instituto Jerónimo Zurita.

ZARCO CUEVAS, J. (1983). Relaciones de pueblos del Obispado de Cuenca. Diputación Provincial de Cuenca. 